\title{
Kinetic Study of Corrosion of Copper in Phosphoric Acid Tert-Butanol Electropolishing Mixtures
}

\author{
Gehan M. El-Subruiti * and A. M. Ahmed \\ Chemistry Department, Faculty of Science, Alexandria \\ University P.O. Box: 426 Ibrahimia, Alexandria 21321, Egypt
}

Received 11 February 2002; Accepted in revised form 20 September 2002

\begin{abstract}
The rate of copper dissolution in presence of phosphoric acid tert-butanol electropolishing mixtures was studied by measuring the limiting current which represents the rate of electropolishing. The rate of dissolution decreases by increasing phosphoric acid concentration, electrode height and the mole fraction of alcohol. The data show that addition of tert-butanol to phosphoric acid decreases the rate of dissolution of copper by an amount ranging from $68 \%$ to $90 \%$ depending on the dielectric constant of mixtures. Thermodynamic parameters are given.
\end{abstract}

Keywords: kinetics, corrosion, electropolishing, phosphoric acid, tert-butanol

\section{Introduction}

Much work has been done on the phenomenon of electroplating since its discovery by Jaquet $[1,2]$, owing to its importance as a metallic finishing process. A great deal of work has been directed to the study of the mechanism of electroplating as well as establishing the optimum polishing conditions for different metals and alloys [3].

Mechanistic studies [2,4,5,6] have revealed that electropolishing is a diffusion controlled reaction which takes place at the limiting current, being this parameter attained most probably when the diffusion layer becomes saturated with $\mathrm{Cu}^{2+}[2,4]$. The value of the limiting current that determines the polishing rate, depends on the rate of mass transfer of $\mathrm{Cu}^{2+}$ from the diffusion layer to the bulk of the solution. The rate of mass transfer depends on the relative movement of the anode and the electrolyte, physical properties of the electrolyte, temperature and geometry of the anode. The

\footnotetext{
*Corresponding author. E-mail address: gehansubruiti@hotmail.com
} 
present work deals with the study of the factors affecting the limiting current of the electropolishing of horizontal copper cylinders in unstirred $\mathrm{H}_{3} \mathrm{PO}_{4}$ solution where the transfer of $\mathrm{Cu}^{2+}$ from the anode surface to the bulk solution is carried out mainly by diffusion and natural correction arising from the differences in density between the interfacial solution (saturated copper phosphate in $\mathrm{H}_{3} \mathrm{PO}_{4}$ ) and the bulk solution $\left(\mathrm{H}_{3} \mathrm{PO}_{4}\right)$.

Previous work on the factors affecting the limiting current [7-10] overlooked the effect of anode geometry, despite its importance in determining the value of the limiting current. Also the corrosion of copper in phosphoric acid was studied previously in the presence of methanol [11] and isopropanol [12] as cosolvents added to water. The present study extends this work into mixtures of tert-butanol in water, as the positive structural contribution to the change in the temperature of maximum density of water [13] is greater for tert-butanol than in the case of methanol or isopropanol mixtures. This is supported by the variation in the extents to which the minimum in the relative partial molar volume of the alcohol is reduced at low mole fractions of the alcohol, $\mathrm{x}_{2}$, [14]; the variation in the extent of the maximum in the ultrasonic absorption [15]; and the shift of the minimum in the excess enthalpy of mixing to lower $x_{2}[16]$; in the sequence methanol-isopropanol-tert-butanol.

\section{Experimental}

\section{Materials}

Pure tert-butanol was further purified [17] by drying over anhydrous calcium sulphates. It was fractionated after filtration from the desiccant. The pure tert-butanol boiled at $82.5^{\circ} \mathrm{C} / 760 \mathrm{~mm}$. Analar grade phosphoric acid was used to make up the solutions of different concentrations ranging from $6-14 \mathrm{M}$ by dilution with water.

\section{Apparatus and procedure}

The cell and electrical circuit used as described in previous work [11]. The cell consisted of rectangular container having dimensions $5 \times 5 \times 10 \mathrm{~cm}$ with electrodes fitting the whole cross-section. The electrodes were rectangular copper sheets of $10 \mathrm{~cm}$ height and $5 \mathrm{~cm}$ width. Electrode separation was $5 \mathrm{~cm}$, a porous PVC diaphragm was used to prevent the stirring effect due to $\mathrm{H}_{2}$ bubbles.

The electrical circuit consisted of a 6 volt d.c. power supply, a variable resistance and a multirange ameter connected in series with the cell. A high impedance voltmeter was 
connected in series with the cell. A high impedance voltmeter was connected in parallel with the cell to measure it potential. Four concentrations of $\mathrm{H}_{3} \mathrm{PO}_{4}$ were used; $6,8,10$ and $12 \mathrm{M}$; all were prepared from, A. R. grade $\mathrm{H}_{3} \mathrm{PO}_{4}$.

The steady state anode potential was measured against a reference electrode consisted of copper wire immersed in the cup of a luggin tube filled with phosphoric acid-alcohol solution similar to that in the cell, the tip of the luggin tube was placed $0.5-1 \mathrm{~mm}$ from the anode.

Polarization curves, from which the limiting current was determined, were plotted by increasing the applied current stepwise and measuring the corresponding steady state potential. Two minutes were allowed for reaching the steady state potential. Before each run, the back of the anode was insulated with polystyrene lacquer and the active surface of them was polished with fine emery paper, degreased with trichloroethylene, washed with alcohol and finally rinsed in distilled water [11].

\section{Rotating cylinder electrode (R.C.E) cell and circuit using rotating copper cylinder}

The apparatus was described in previous work [11]. The electrical circuit consisted of a 12 volts D.C. power supply, and a multirange ammeter connected in series with the cell. A voltmeter was connected in parallel with the cell to measure its voltage. The anode consisted of $\mathrm{Cu}$ metal cylinder $0.98 \mathrm{~cm}$ diameter and $2 \mathrm{~cm}$ length. The sides and back of cylinder, and the drive shaft were insulated with epoxy resin.

The cathode was a cylindrical copper metal electrode of $12 \mathrm{~cm}$ diameter. This electrode also acted as the reference electrode by virtue of its large surface area, compared to that of the anode.

\section{Results and Discussion}

\section{Variation of rate of corrosion with solvent parameters and temperatures}

Fig. 1 is a typical current-potential curve obtained at different mole fractions of tertbutanol. As shown in Table 1, the limiting current decreased when higher mole fractions of tert-butanol were used. Fig. 2 shows the relationship between the limiting current and the mole fraction of the alcohol. From Fig. 2 we conclude that $I \alpha x^{-0.61}$. This value differed from that reported when methanol was used [11], where I $\alpha \mathrm{x}^{-0.31}$. The decrease of the rate of dissolution with increasing mole fraction of tertbutanol, may be due to the fact that the steric hindrance of the branched tert-butanol is greater than in water. Also, these findings were interpreted on the basis that the metal 
surface is preferentially solvated by the organic solvent molecule $[18,19]$. Consequently the transmission of the metal ion through a double layer at the electrode surface requires maximum energy to an increase in $\Delta \mathrm{H}^{*}$. This would result in a decrease in the rate of corrosion or dissolution rate of the copper.

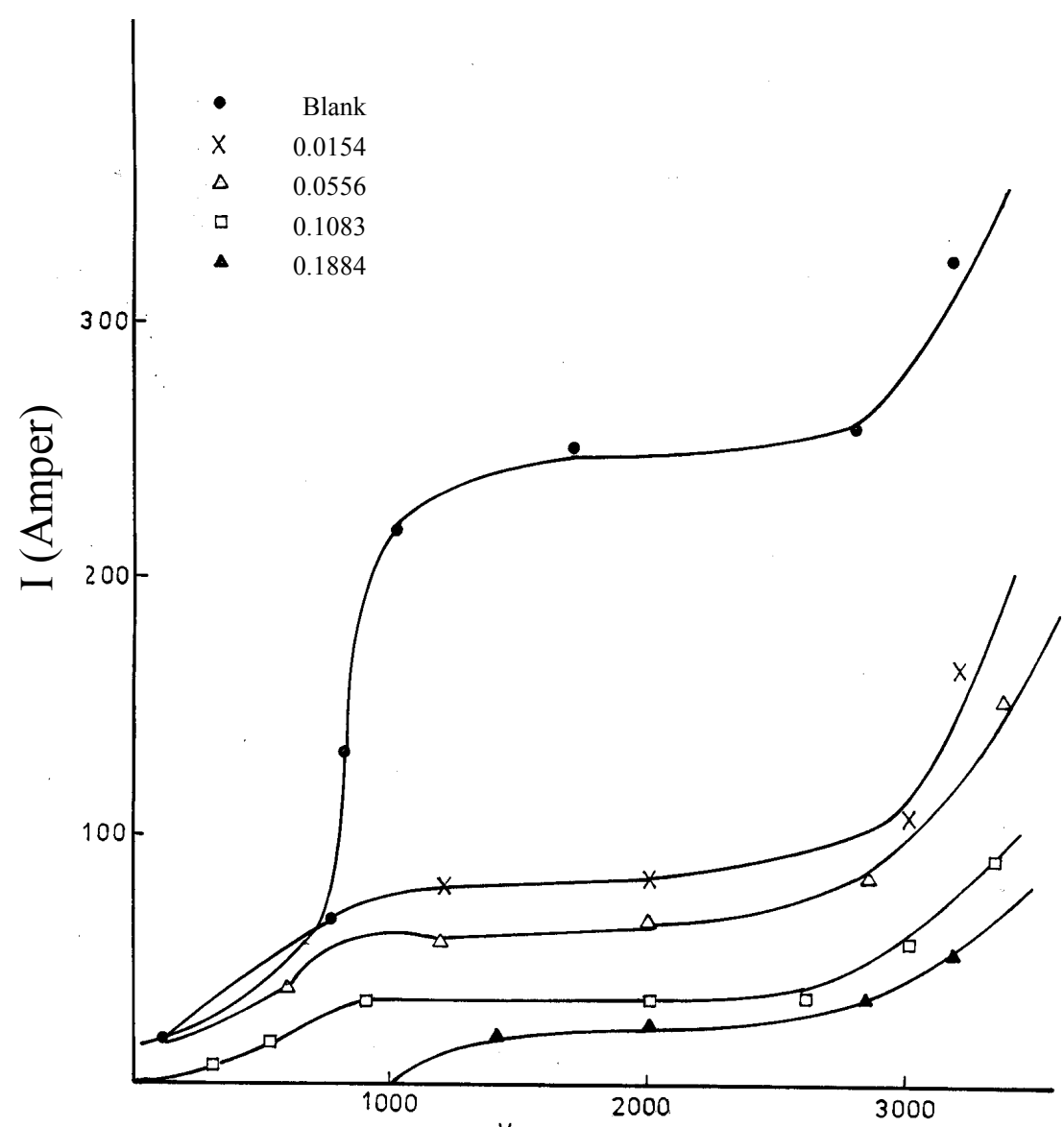

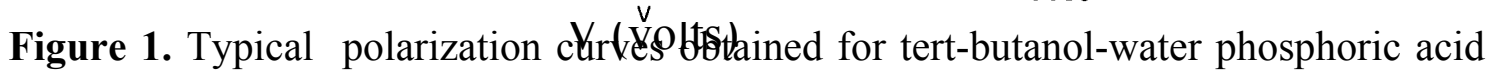
mixtures at different mole fractions at $25^{\circ} \mathrm{C}$.

Table 1. The calculated limiting current $(\mathrm{mA})$ for the corrosion of copper in the presence of tert-butanol mixtures at different temperatures and different compositions. Mole Fraction Limiting Current (mA)

\begin{tabular}{ccccc}
\cline { 2 - 5 } $\mathrm{x}_{2}$ & $20{ }^{\circ} \mathrm{C}$ & $25^{\circ} \mathrm{C}$ & $30{ }^{\circ} \mathrm{C}$ & $35^{\circ} \mathrm{C}$ \\
\hline 0.0154 & 113.9 & 138.8 & 168.0 & 202.1 \\
0.0566 & 109.5 & 124.6 & 141.3 & 159.5 \\
0.1083 & 103.8 & 118.1 & 133.8 & 151.1 \\
0.1884 & 87.2 & 103.0 & 212.1 & 141.5 \\
0.305 & 64.7 & 71.3 & 78.3 & 85.7 \\
1.000 & 27.9 & 30.1 & 32.3 & 34.7 \\
\hline
\end{tabular}




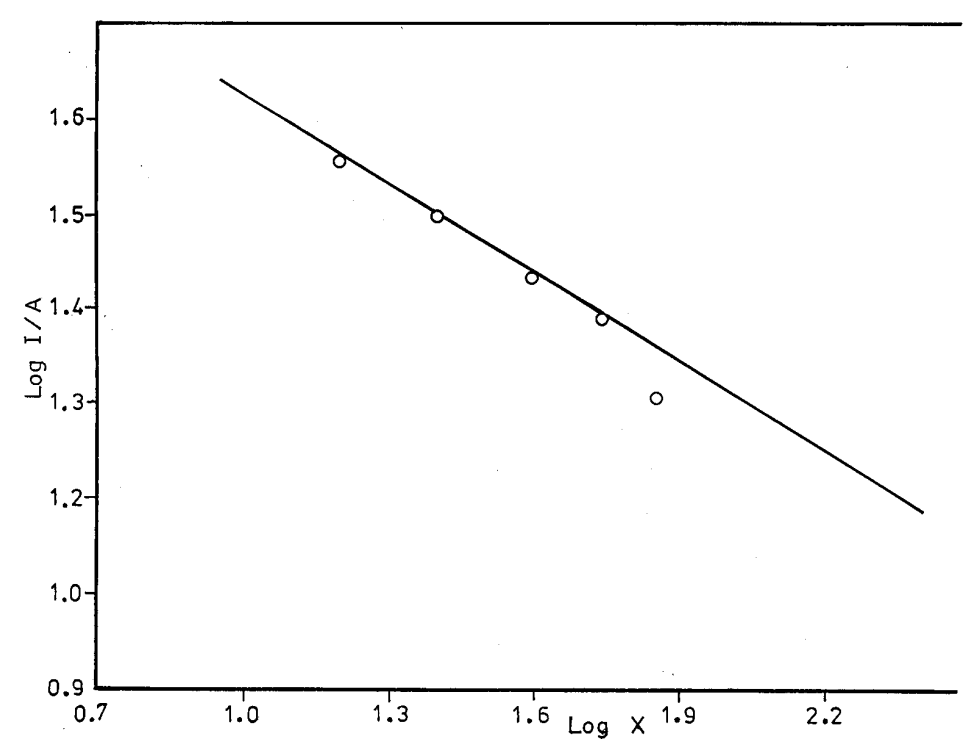

Figure 2. Effect of mole fraction of tert-butanol on the limiting current density in $10 \mathrm{M}$ $\mathrm{H}_{3} \mathrm{PO}_{4}$ at $25^{\circ} \mathrm{C}$.

It was found that, the rate of dissolution of copper in the phosphoric acid at different temperature decreased by decreasing the mole fraction of tert-butanol. At each of the above solvent compositions a linear plot was obtained for $\log \mathrm{I}_{\ell}$ against the reciprocal of the absolute temperatures. The values of $\mathrm{E}$, the energy $\Delta \mathrm{S}^{*}$ the enthalpy; $\Delta \mathrm{H}^{*}$, the entropy and $\Delta \mathrm{G}^{*}$, the free energy of activation given in Table 2 were calculated by applying a least square computer program to all the individual values for $\mathrm{I}_{\ell}$ and for all the temperatures at each solvent composition. This procedure also produced the standard errors for $\Delta \mathrm{H}^{*}, \Delta \mathrm{S}^{*}$ and $\Delta \mathrm{G}^{*}$ recorded in Table 2 , all of which were considered to be within acceptable limits.

\section{Effect of electrolyte concentration on the polishing current}

Fig. 3 shows the dependence of the electropolishing current on the bulk concentration of $\mathrm{H}_{3} \mathrm{PO}_{4}$, the limiting current density decreases with the increase of $\mathrm{H}_{3} \mathrm{PO}_{4}$ but the values of $\mathrm{I}_{\ell}$ in the acid alcohol water mixture were lower than in water-acid mixtures. From a practical point of view, we can comment on the above result, that it is preferable to use relatively high organic solvent percentage to inhibit polishing or dissolution of metal at the same $\mathrm{H}_{3} \mathrm{PO}_{4}$ concentration. This is in agreement with the finding of other authors who worked within the same range of concentration using another anode geometry [7$10]$. 


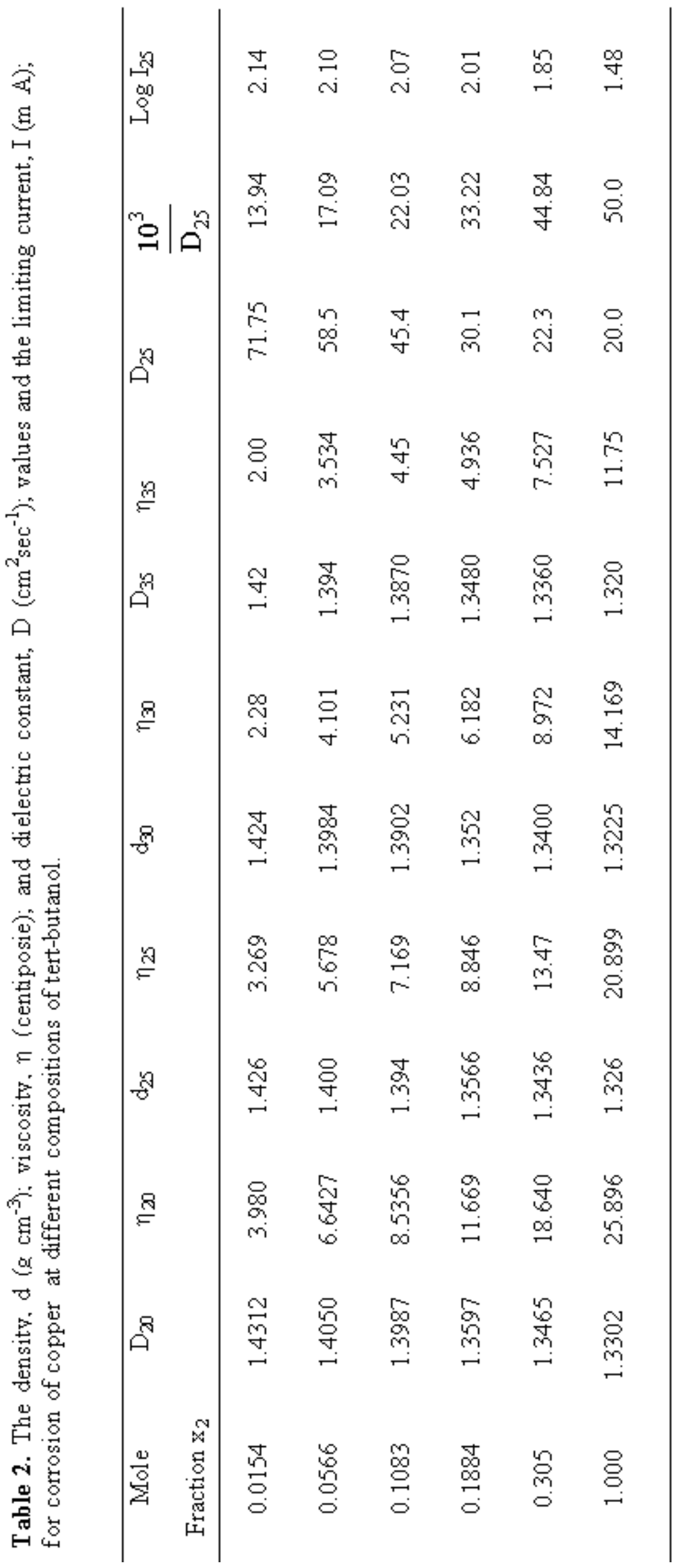




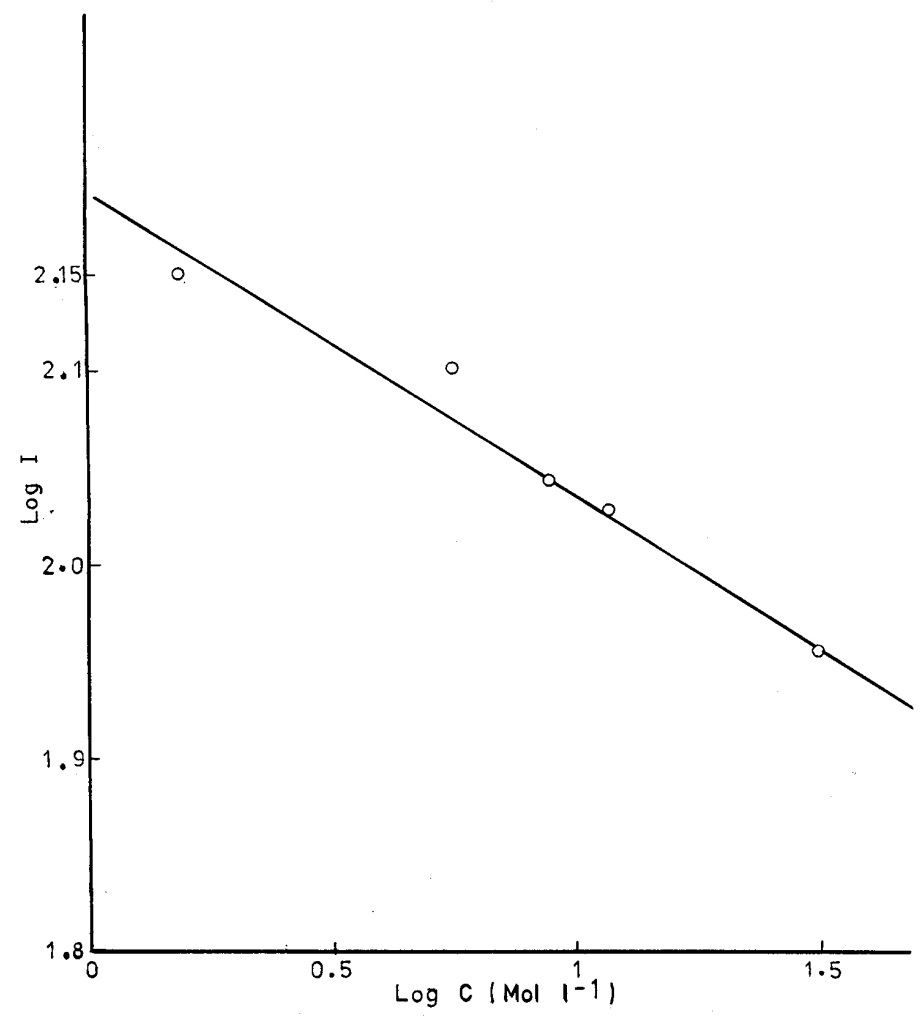

Figure 3. Effect of phosphoric acid concentration on the limiting current at $25^{\circ} \mathrm{C}$.

The effect of $\mathrm{H}_{3} \mathrm{PO}_{4}$ concentration on the value of the limiting current can be explained on the basis of mass transfer according to the following equation [11].

$$
I_{\ell}=\frac{Z F D}{\delta}-C_{C u^{2+}}
$$

where $\mathrm{Z}=$ valency, $\mathrm{F}=$ Faraday, $\mathrm{D}=$ diffusion coefficient and $\delta=$ diffusion layer thickness.

Here, increasing $\mathrm{H}_{3} \mathrm{PO}_{4}$ concentration decreases the saturation solubility limit of copper phosphate [20], $\left(\mathrm{Cu}^{2+}\right.$ - with a consequent decrease in the limiting current according to equation 1. i.e. the rate of copper dissolution will go down).

As shown in Table 2, by increasing the tert-butanol concentration, the limiting current decreases, this is due to that the viscosity of the organic-water- $\mathrm{H}_{3} \mathrm{PO}_{4}$ is greater than that of water- $\mathrm{H}_{3} \mathrm{PO}_{4}$ which results in an increase in the diffusion layer thickness $(\delta)$ and also in the diffusivity of $\mathrm{Cu}^{2+}$. Also the solubility of copper phosphate in the presence of tert-butanol is lower than in water acid medium, so the saturation of the solution is attained quickly and the rate decreases.

However, Fig. 3 gives the relation between the limiting current and the concentration of $\mathrm{H}_{3} \mathrm{PO}_{4}$ at constant concentration of tert-butanol. It is found that $\mathrm{I} \alpha \mathrm{C}^{-0.833}$, this value 
differs from that in the presence of methanol [11] as a co-solvent added to water where I $\alpha \mathrm{C}^{1.9}$.

\section{Effect of the electrode height on the polishing current}

Fig. 4 shows that the limiting current density increases with the decrease in height where, in electropolishing and in general for anodic dissolution of metals, the direction of flow of hydrodynamic boundary layer and the diffusion layer increases in downward direction i.e. the resistance to mass transfer increases from downward direction. Accordingly the total limiting current density increases in upward directions of the anode. This explains why polishing is attained at the upper parts of the electrode before the lower parts at the limiting current region, this was confirmed by visual observation during electropolishing. It is found that $\mathrm{I} \alpha \mathrm{H}^{-0.455}$, which differs from that of methanol [11] where $\mathrm{I} \alpha \mathrm{H}^{-0.532}$ due to steric hindrance din the case of tert-butanol is grater than that in the case of methanol.

Fig. 5 and Table 4 show an overall correlation between $\mathrm{I}_{\ell}$ and all variables used. The data can be represented by the following equation

$$
\mathrm{I}=39.8\left(\mathrm{X}^{-0.6} \mathrm{H}^{-0.455} \mathrm{C}^{-0.833}\right)
$$

However this equation differs from that for methanol [11] where it was found that

$$
\mathrm{I}=0.337\left(\mathrm{X}^{-0.31} \mathrm{H}^{-0.532} \mathrm{C}^{-0.19}\right)
$$

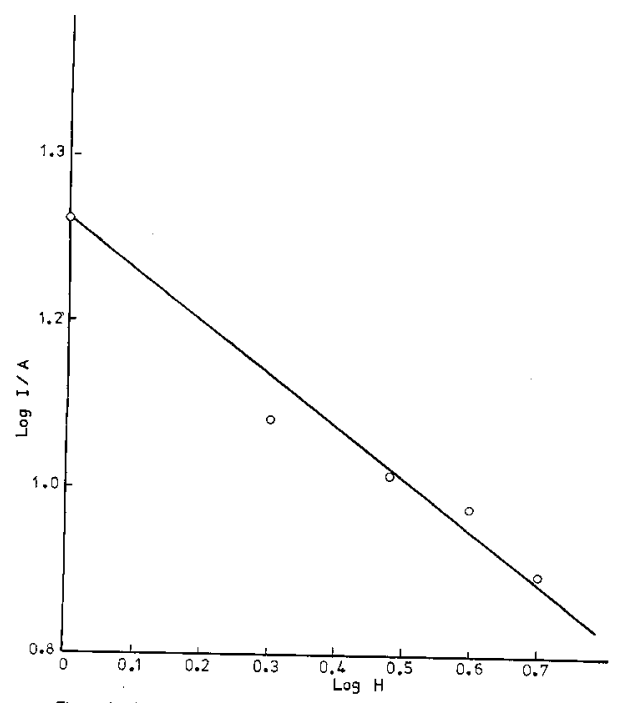

Figure 4. Effect of electrode height (mm) on the limiting current density at $25^{\circ} \mathrm{C}$. 


\section{Variation of the rate of corrosion with solvent parameter}

If $\left(\mathrm{I}_{\ell}\right)$ is the limiting current in absence of organic substance $\left(\mathrm{I}_{\ell}\right)_{\text {org. }}$. in presence of the organic substance, then the percentage of inhibition can be calculated according to eq. (4), where

$$
\% \text { inhibition }=\frac{\left(I_{\ell}\right)_{\text {blank }}-\left(I_{\ell}\right)_{\text {organc }}}{\left(I_{\ell}\right)_{\text {blank }}} \times 100
$$

Fig. 6 gives the relationship between the percentage of inhibition and the concentration of alcohol. It is evident that percentage inhibition increases with concentration.

Also as shown in Table 2 the rate of corrosion decreases as the dielectric constant $\left(D_{s}\right)$ of tert-butanol-water mixture decreases, where $D_{s}$ values are interpolated from Åkerlöf's values. This decrease may be due to the smaller dielectric constant, which usually discourages dissolution.

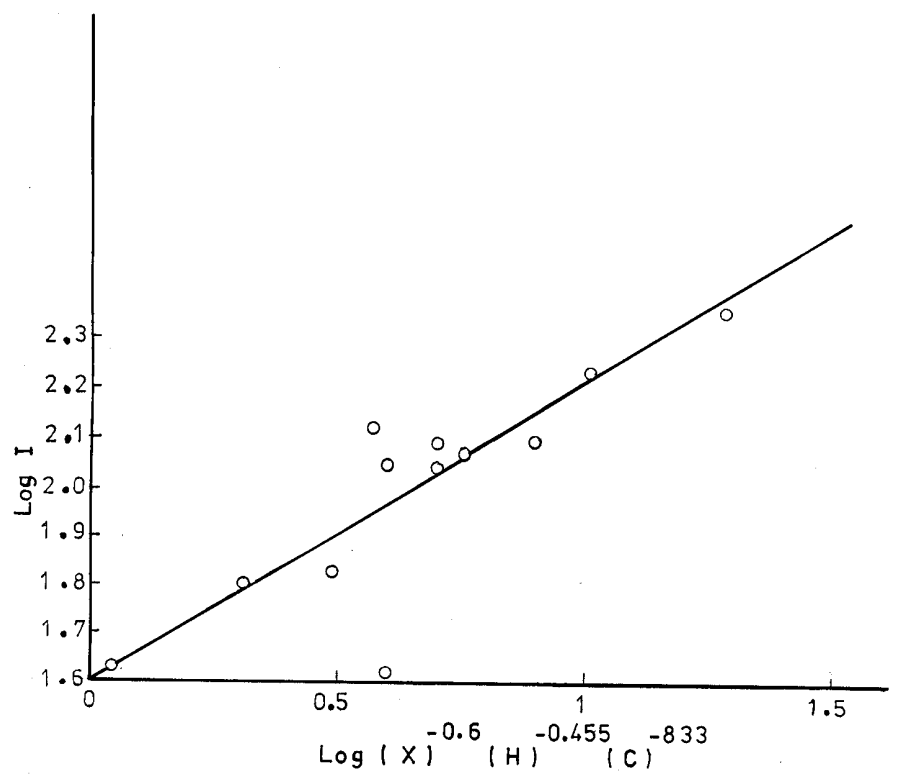

Figure 5. General correlation of free convection.

\section{Variation of transition state parameter with solvent composition}

Table 3 shows that $\Delta \mathrm{G}^{*}$ varies little with the solvent composition. This is because of the competing effects of $\Delta \mathrm{H}^{*}$ and $\Delta \mathrm{S}^{*}$ values. It is found that $\Delta \mathrm{S}^{*}$ values are negative indicating an ordered system which is stabilized by solvation. 


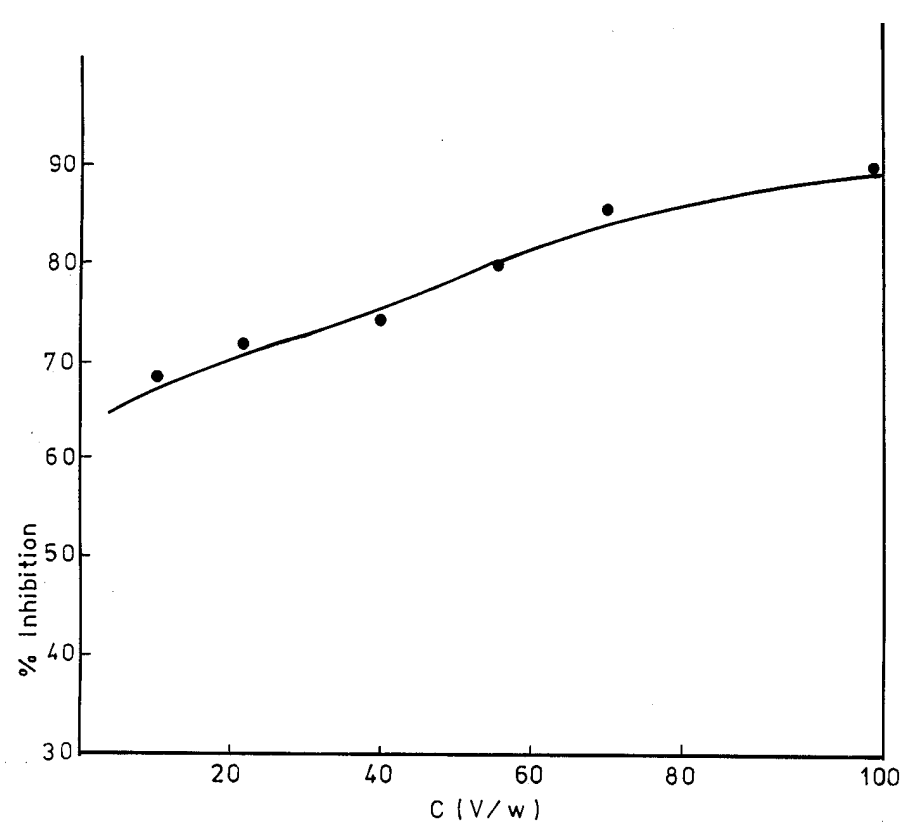

Figure 6. The relationship between percentage inhibition and tert-butanol concentration at $25^{\circ} \mathrm{C}$.

In Fig. $7 \Delta \mathrm{H}^{*}$ and $\Delta \mathrm{S}^{*}$ are plotted against the mole fraction of tert-butonol. The variations in $\Delta \mathrm{H}^{*}$ and $\Delta \mathrm{S}^{*}$, are mirror image to each other due to the compensating effects of both $\Delta \mathrm{H}^{*}$ and $\Delta \mathrm{S}^{*}$. These parameters show a well defined minimum in $\Delta \mathrm{H}^{*}$ (or maximum $-\Delta \mathrm{S}^{*}$ ) in the region of $\mathrm{x}_{2} \sim 0.05$, where the decrease in the partial molar volume $\bar{V}_{2}-V_{2}^{o}$ shows $[14,17]$ a sharp minimum of water/tert-butanol mixtures. There is also a maximum at $\mathrm{x}_{2} \sim 0.2$ where ultra sound absorption shows [5] a sharp maximum in water/tert-butanol mixtures. This is explained by the exclusion of the alkyl groups from the Frank-type "flickering icebergs" of structured water [22], leading to a concentration of the alkyl groups in the limited space intrinsic between the "icebergs". $\bar{V}_{2}-V_{2}^{o}$ reaches a minimum as $\mathrm{x}_{2}$ rises, and $\bar{V}_{2}$ approaches $V_{2}^{o}$ for the pure alcohol when sufficient alkyl groups are clustered together.

The isokinetic plot of $\Delta \mathrm{H}^{*}$ against $\Delta \mathrm{S}^{*}$ for different solvent compositions was found to be linear and the isokinetic temperature $(\beta)$ was computed from the slope of the plot as $220^{\circ} \mathrm{K}$ This value is lower than that of the experimental temperature, indicating that the rate of the reaction is entropy controlled, where solute-solvent interaction plays an important role in the corrosion process [23-27]. 


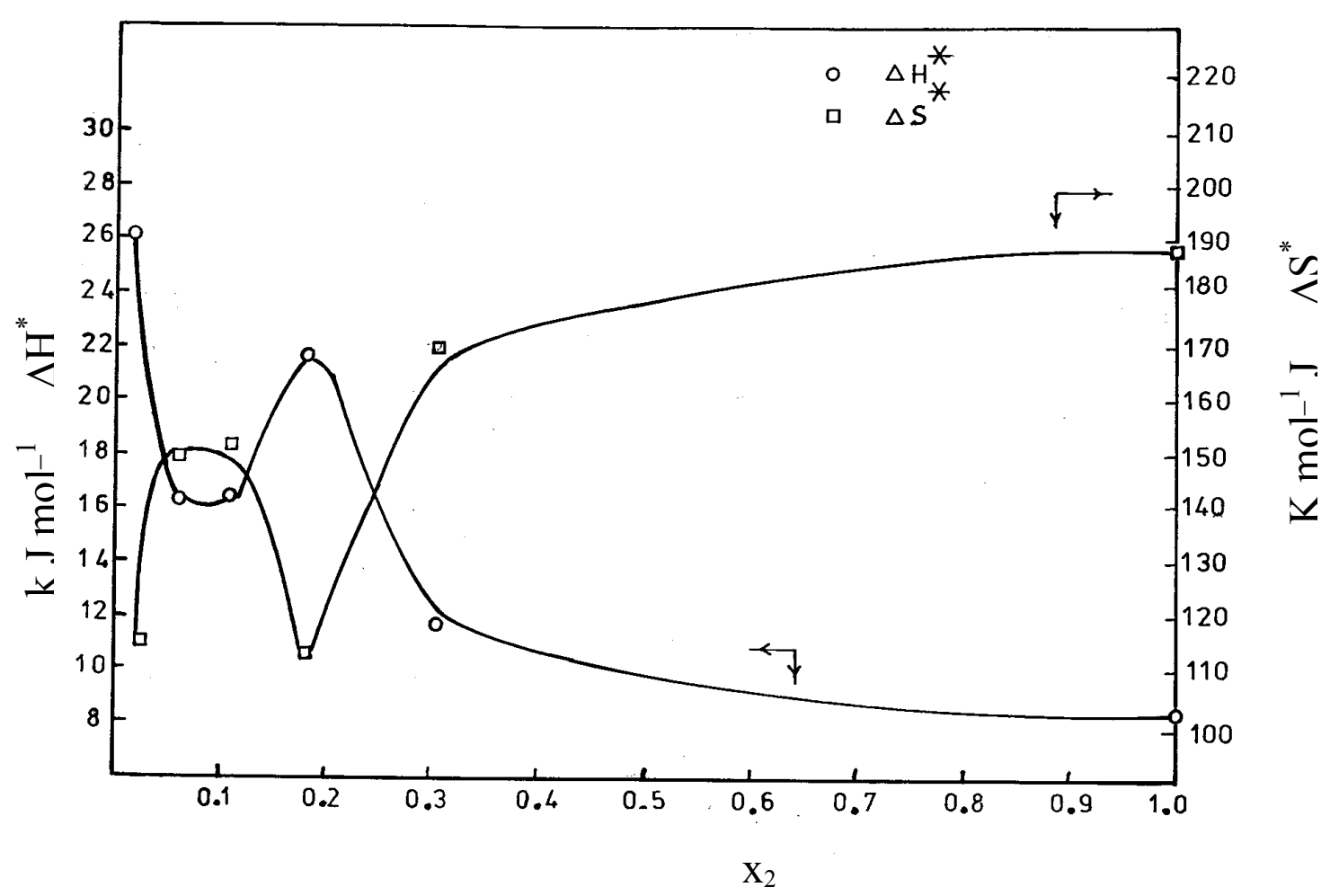

Figure 7. The relationship between $\Delta \mathrm{H}^{*}$ and $\Delta \mathrm{S}^{*}$ with the mole fraction $\mathrm{x}_{2}$ of tertbutanol mixture.

Table 3. Thermodynamic parameters for the corrosion of copper in tert-butanol water mixtures.

\begin{tabular}{ccccc}
\hline $\begin{array}{c}\text { Mole fraction } \\
\mathrm{X}_{2}\end{array}$ & $\begin{array}{c}\mathrm{E} \\
\mathrm{kJ} \mathrm{mol}^{-1}\end{array}$ & $\begin{array}{c}\Delta \mathrm{H}^{*} \\
\mathrm{~kJ} \mathrm{~mol}^{-1}\end{array}$ & $\begin{array}{c}-\Delta \mathrm{S}^{*} \text { at } 25^{\circ} \mathrm{C} \\
\mathrm{JK}^{-1} \mathrm{~mol}^{-1}\end{array}$ & $\begin{array}{c}\Delta \mathrm{G}^{*} \\
\mathrm{~kJ}^{-1} \mathrm{~mol}^{-1}\end{array}$ \\
\hline 0.0154 & $28.7 \pm 2.1$ & $26.3 \pm 2.1$ & $115.8 \pm 6.1$ & $60.8 \pm 4.2$ \\
0.0566 & $18.8 \pm 1.5$ & $16.4 \pm 1.5$ & $149.9 \pm 5.0$ & $61.1 \pm 3.1$ \\
0.1083 & $18.8 \pm 2.3$ & $16.3 \pm 2.3$ & $150.5 \pm 7.6$ & $61.2 \pm 4.5$ \\
0.1884 & $24.3 \pm 6.0$ & $21.8 \pm 6.0$ & $113.3 \pm 20.0$ & $61.5 \pm 11.9$ \\
0.305 & $14.1 \pm 1.4$ & $11.6 \pm 1.4$ & $170.4 \pm 4.7$ & $62.4 \pm 2.8$ \\
1.00 & $11.0 \pm 0.7$ & $11.0 \pm 0.7$ & $188.0 \pm 2.3$ & $64.6 \pm 1.4$ \\
\hline
\end{tabular}

\section{Effect of stirring and applications of dimensional analysis}

The effect of the speed of rotation on the rate of metal deposition can also be used to determine whether the electrodeposition process is a diffusion or chemically controlled process. If the rate of deposition increases by increasing the speed of rotation, then the reaction is diffusion controlled. However, if the rate of deposition is independent of the rotation, so the reaction is likely to be chemically controlled.

The angular velocity, $\omega$, is given by: 


$$
\omega=\frac{2 \pi r p m}{60}
$$

Fig. 8 shows the relation between $\mathrm{I}_{\mathrm{L}}$ and $\omega$ at different concentrations of tert-butanol at. $25^{\circ} \mathrm{C}$. Straight lines were obtained and the limiting current density increased with increasing rotation speed, which indicates that the electropolishing reaction is a diffusion controlled reaction.

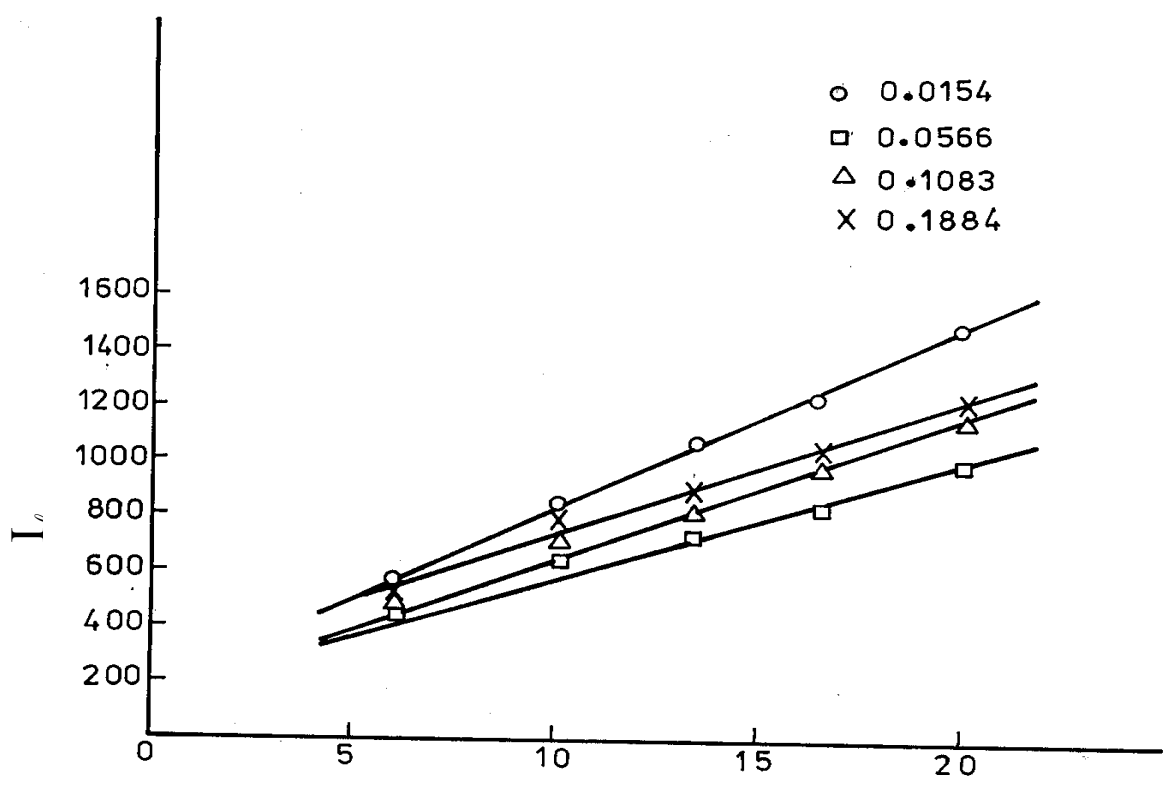

$\omega$

Figure 8. The relationship between $I_{e}$ and $\omega$ at different concentration of tert-butanol at $25^{\circ} \mathrm{C}$.

The diffusion coefficient of $\mathrm{Cu}^{2+}$ ions, $\mathrm{D}$, in different solutions was determined from the values of limiting current densities using Eisenberg equation

$$
\mathrm{I}_{\mathrm{L}}=0.079 \ln \mathrm{FC}_{\mathrm{b}} \mathrm{U}^{0.7} \mathrm{~d}_{\mathrm{I}}^{-0.3} v^{-0.344} \mathrm{D}^{0.644}
$$

where $\mathrm{n}$ is the number of exchanged electrons, $\mathrm{F}$ is Faraday's constant, $\mathrm{nF}$ is called "Faradaic equivalence", $\mathrm{C}_{\mathrm{b}}$ is the bulk concentration $\left(\mathrm{mol} \mathrm{cm}^{-3}\right), \mathrm{U}$ is the peripheral velocity $=\omega \mathrm{r}$ in $\mathrm{cm} \mathrm{rad} \mathrm{s}^{-1}$ (where, $\omega$ is the angular velocity in rad. $\mathrm{S}^{-1}, \mathrm{r}$ is the radial distance in $\mathrm{cm}$ ) or $\mathrm{U}=2 \pi \omega \mathrm{r} \mathrm{s}^{-1}, \mathrm{~d}$ is the characteristic length for the rotating cylinder $=$ the diameter of the cylinder in $\mathrm{cm}, \mathrm{D}$ is the diffusion coefficient for the metal ions $\left(\mathrm{Cu}^{2+}\right.$ ions in our case) in $\mathrm{cm}^{2} \mathrm{~s}^{-1}$, and $\mathrm{v}$ is the kinematic viscosity in stoke $(\mathrm{v}=\eta / \rho)$.

Values of $\mathrm{D}$ and $v$ for all solutions under different conditions are also recorded in Table IV. The diffusion coefficient; $\mathrm{D}$, of $\mathrm{Cu}^{2+}$ ions in solutions containing organic substances 
decreases due to the increase in the interfacial viscosity; $\eta$ in accordance with the Stokes-Einstein equation:

$$
\frac{\eta D}{T}=\text { const }
$$

where $\eta$ is the viscosity of solution $\left(\mathrm{g} \cdot \mathrm{cm}^{-1} \cdot \mathrm{s}^{-1}\right)$, D is the diffusion coefficient of copper ions $\left(\mathrm{cm}^{2} \mathrm{~s}^{-1}\right)$ and $\mathrm{T}$ is the absolute temperature $(\mathrm{K})$.

The present results agree with the polarographic studies conducted in solutions containing surfactants where it was found that the diffusion current decreased in the presence of surfactants.

The conventional RCE system is designed so that the inner cylinder rotates and creates a turbulent flow in the field. When the inner cylinder is rotated slowly, a laminar flow pattern can be maintained. However, laminar flow fluid moves in circular pattern about the axis with no radial component. Thus, there is no convection in the radial direction, and no enhancement of mass transport due to fluid flow. Consequently, an RCE is rarely operated in the laminar flow regime in electrochemical studies.

To obtain an overall mass transfer correlation under the present conditions by using the method of dimensional analysis we suppose:

$$
\mathrm{Sh}=\mathrm{a} \operatorname{Re}^{\mathrm{b}} \cdot \mathrm{Sc}^{0.33}
$$

where Sh, Re and Sc are the Sherwood $(\mathrm{Sh}=\mathrm{kl} / \mathrm{D})$, Reynolds $(\mathrm{Re}=\mathrm{IU} / \mathrm{v})$ and $\mathrm{Schmidt}$ $(\mathrm{Sc}=\mathrm{v} / \mathrm{D})$ numbers, respectively, and $\mathrm{a}$ and $\mathrm{b}$ are empirical constants, $\mathrm{C}=0.33$ (indicating forced convection).

Table 4 summarizes the values of dimensionless groups Sh, Sc, and Re, used to obtain the correlations. By plotting $\log \left[\frac{S h}{S c^{0.33}}\right]$ against $\log (\mathrm{Re})$, a straight line is obtained.

The slope of the line gives the constant $b$ while the intercept gives the other constant $a$. Fig. 9 shows the mass transfer correlation for all parameters used in electropolishing. From this figure, the data can be correlated by the following equation

$$
\mathrm{Sh}=0.925(\mathrm{Sc})^{0.33}(\mathrm{Re})^{0.68}
$$

with average of deviation $\pm 1.2012 \%$. 
Table 4. The general correlation of free convective mass transfer at $25^{\circ} \mathrm{C}$.

\begin{tabular}{|c|c|c|c|c|c|c|c|c|}
\hline $\begin{array}{c}\text { Conc } \\
\text { X }\end{array}$ & rpm & $\begin{array}{c}\mathrm{I}_{\ell} \\
\mathrm{mA} \cdot \mathrm{cm}^{2}\end{array}$ & $\mathrm{~cm}^{2} \mathrm{~s}^{-1}$ & $\begin{array}{l}\mathrm{K} \times 10^{3} \\
\mathrm{~cm}^{2} \mathrm{~s}^{-1}\end{array}$ & $\begin{array}{c}\text { D. } 10^{6} \\
\mathrm{~cm}^{2} \mathrm{~s}^{-1}\end{array}$ & $\mathrm{Sh}$ & $\mathrm{Sc}$ & $\operatorname{Re}$ \\
\hline \multirow{5}{*}{0.305} & 125 & 75 & \multirow{5}{*}{0.0144} & 2.250 & 1.73 & 2601 & 8676 & 5373 \\
\hline & 250 & 94 & & 2.829 & 1.17 & 4837 & 12816 & 10746 \\
\hline & 375 & 122 & & 3.710 & 1.15 & 6451 & 13043 & 16116 \\
\hline & 500 & 137 & & 4.150 & 9.99 & 8383 & 15149 & 21492 \\
\hline & 625 & 158 & & 4.831 & 1.00 & 9680 & 14978 & 26800 \\
\hline \multirow{5}{*}{0.1884} & 125 & 82 & \multirow{5}{*}{0.0156} & 2.490 & 2.040 & 2441 & 7647 & 5166 \\
\hline & 250 & 98 & & 2.973 & 1.273 & 4693 & 1228313 & 10320 \\
\hline & 375 & 124 & & 3.780 & 1.181 & 6400 & 1091405 & 15480 \\
\hline & 500 & 143 & & 4.423 & 1.102 & 8008 & 4 & 20606 \\
\hline & 625 & 173 & & 5.102 & 1.081 & 9410 & 14311 & 25803 \\
\hline \multirow{5}{*}{0.1083} & 125 & 87 & \multirow{5}{*}{0.0157} & 2.1790 & 2.172 & 2389 & 7235 & 5133 \\
\hline & 250 & 103 & & 1.338 & 1.350 & 4638 & 1804 & 16270 \\
\hline & 375 & 139 & & 1.372 & 1.382 & 6105 & 11544 & 15410 \\
\hline & 500 & 155 & & 1.202 & 1.202 & 7798 & 13193 & 20540 \\
\hline & 625 & 186 & & 1.1821 & 1.270 & 9170 & 13418 & 25680 \\
\hline \multirow{5}{*}{0.0566} & 125 & 93 & \multirow{5}{*}{0.0160} & 2.795 & 2.162 & 2596 & 7441 & 5040 \\
\hline & 250 & 108 & & 3.234 & 1.480 & 4466 & 11033 & 10080 \\
\hline & 375 & 146 & & 4.343 & 1.493 & 5870 & 10810 & 15112 \\
\hline & 500 & 161 & & 4.82 & 1.530 & 7610 & 12700 & 20150 \\
\hline & 625 & 192 & & 5.290 & 1.632 & 9182 & 13912 & 25190 \\
\hline \multirow{5}{*}{0.0154} & 125 & 98 & \multirow{5}{*}{0.0163} & 2.983 & 2.750 & 2166 & 11745 & 4950 \\
\hline & 250 & 114 & & 3.374 & 1.582 & 4298 & 20580 & 9890 \\
\hline & 375 & 151 & & 4.505 & 1.632 & 5697 & 40450 & 14845 \\
\hline & 500 & 213 & & 6.351 & 1.74 & 6449 & 16400 & 19780 \\
\hline & 625 & 236 & & 6.902 & 1.97 & 7866 & 18670 & 24730 \\
\hline
\end{tabular}

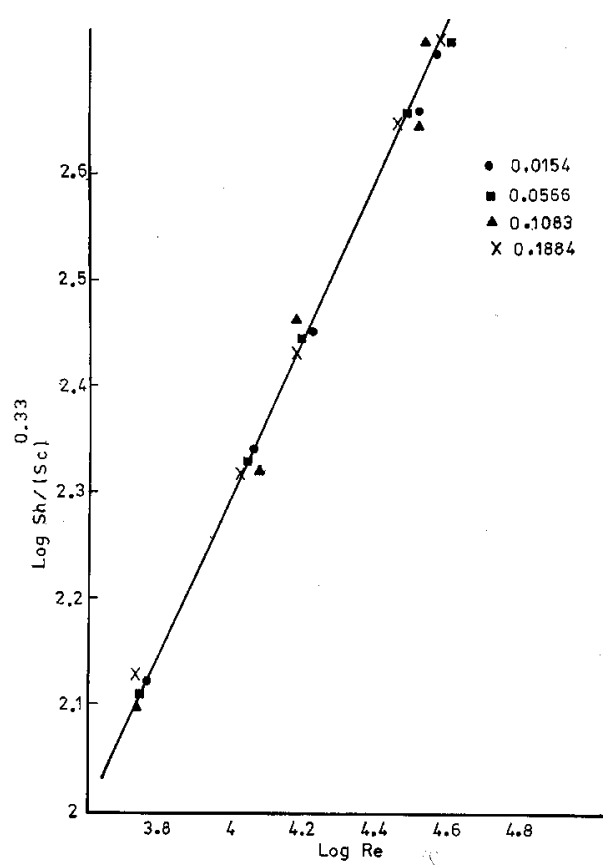

Figure 9. The relationship between $\log \mathrm{Sh} /(\mathrm{Sc})^{0.33}$ and $\log$ Re for tert-butanol at $25^{\circ} \mathrm{C}$. 


\section{Conclusions}

The study of the effect of tert-butanol and phosphoric acid on the electropolishing process led to some important results.

a) The rate of electropolishing decreases by increasing $\mathrm{H}_{3} \mathrm{PO}_{4}$ concentration at constant concentration of tert-butanol.

b) The rate of electropolishing decreases by increasing tert-butanol concentrations.

c) The rate of electropolishing decreases by increasing anode heights of electrode.

d) The rate of electropolishing increases by increasing the temperature.

\section{References}

1. P.A. Jaquet, Nature 135 (1935) 1076.

2. P.A. Jaquet, Trans. Electrochem. Soc. 69 (1936) 629.

3. W.J. Tegart, G. Mc, The Electrolytic and Chemical Polishing of Metals, Pergamon Press, 1959.

4. W.G. Elmore, J. Applied Physics 10 (1939) 724.

5. J. Edwards, J. Electrochem. Soc. 100 (1953) 139.

6. Z. Zembima, W. Michalik, Bull Acad. Pol. Sci. 1115 (1957) 1073.

7. D.R. Gabe, Corrosion Science, 12 (1972) 113.

8. R.W.K. Honeycombe, R.R.J. Hughan, Counc. Sci. Ind. Res. Aust. 20 (1947) 297.

9. A. Hickling, J.K. Higgins, Trans Inst. Met. Fin. 29 (1953) 274.

10. T.P. Hoar., G.P. Rothwell, Electrochem. Acta. 9 (1964) 135.

11. G.M. El-Subruiti, A.M. Ahmed, M.N.U. El-Saraf, Scientist Phyl. Science 7 (1995) 18.

12. A.A. Taha, A.M. Ahmed, Anti. Corrosion Method and Materials 41 (1994) 9.

13. G. Wada, S. Umeda, Bull. Chem. Soc. Japan 35 (1962) 1797.

14. K. Nakanishi, Bull. Chem. Soc. Japan 33 (1960) 793.

15. J. Andreae, P.P. Edmonds, J.F. Mckellar, J.F. Custica, A. 15, 74 (1965), Blandomer, M. J. Introduction to Chemical Ultrasonic, Academic Press, London, 1973, Chap II. 16. Y. Lu, J. Chem. Eng. Data 10 (1965) 216.

17. G. M. El-Subruiti, I.M. Sidahmed, C.F. Wells, Int. J. Chem. Kinet. 24 (1992) 563.

18. R.F. Hudson, B.J. Saville, J. Chem. Soc. (1955) 4114. 
19. W. Jaenick, P.H. Schweitzer, Z. Phys. Chem. N. F., 52 (1967) 104.

20. M.G. Fouad, F.N. Zein, M.I. Ismail, Electrochim Acta 16 (1971) 1447.

21. G.A. Åkelrlöf, J. Amer. Chem. Soc. 54 (1932) 4125.

22. H.S. Frank, M.W.Evans, J. Chem. Phys. 13 (1945) 507; H.S. Frank, Y. Wen, Faraday Soc. Discuss. 24 (1957) 133; W. Laiden, G. Némelhy, J. Phys. Chem. 74 (1970) 350 .

23. G.M. El-Subruiti, I.M. Sidahmed, C.F. Wells, Int. J. Chem. Kinet. 22 (1990) 891.

24. G.M. El-Subruiti, I.M. Sidahmed, C.F. Wells, Int. J. Chem. Kinet. 23 (1991) 150, 161.

25. G.M.El-Subruiti, Transition, Met. Chem. 25 (1999) 219.

26. G.M.El-Subruiti, S.S. Massoud, Transition, Met. Chem. 25 (2000) 344.

27. G.M.El-Subruiti, Int. J. Chem. Kinet. 33 (2001) 431. 